\title{
Supporting Child Welfare Traineeship Students through an Online Peer Network
}

\author{
Stephanie Bosco-Ruggiero \\ Sharon Kollar \\ Virginia C. Strand \\ Robin Leake
}

\begin{abstract}
This article describes the implementation of an online peer network for social work traineeship students pursuing or continuing careers in child welfare. Literature on best principles and practices for facilitating an online community is reviewed, and an explanation of how these best practices were used is provided. Initial program design and program developments, which took place over four years, are described. An overview of the evaluation data and how the program evaluation was carried out is presented. The article concludes with a discussion about successes and challenges experienced in building the peer network and further research needed to understand benefits of the use of online communities and social media in social work education.
\end{abstract}

Keywords: Online communities, social media, traineeship, evaluation, social work education

Increasingly, social media and online communities are being used in social work practice, administration, research, and education: to facilitate inter- and intra- agency collaboration and build communities of practice or professional networks (Greenhow \& Robelia, 2010); in professional practice with clients (Giffords, 2009; Mishna, Bogo, Root, Sawyer, \& Khoury-Kassabri, 2012); to disseminate information (Hitchcock \& Battista, 2013); to support social work education and continuous learning (Davis \& Goodman, 2014; Dunworth, 2009; Kilpeläinen, Päykkönen, \& Sankala, 2011; Moore, 2008; Quinney, 2005); to help bridge research and practice (Lewis, Koston, Quartley, \& Adsit, 2010); and in community organizing and advocacy (Edwards \& Hoefer, 2010; Parrott \& Madoc-Jones, 2008; Young \& Delves, 2009).

Online community platforms used in social work include wikis (Kilpeläinen et al., 2011), blog sites (Hickson, 2012; Young \& Delves, 2009), email list serves (Murty, Gilmore, Richards, \& Altilio, 2012), discussion forums/boards (Quinney, 2005), and Ning sites (Davis \& Goodman, 2014). Social media used in social work includes LinkedIn, Facebook, and Twitter (Hitchcock \& Battista, 2013). Online communities now offer many of the same features as social media and vice versa. For example, many community

\footnotetext{
Stephanie Bosco-Ruggiero, MA is a doctoral student at the Fordham University Graduate School of Social Service, New York, NY and former Student Peer Network Coordinator at the National Child Welfare Workforce Institute (boscoruggier@fordham.edu). Sharon Kollar, LMSW is the LINKD Coordinator at the National Child Welfare Workforce Institute and adjunct instructor at the School of Social Welfare at the University at Albany, Albany, NY. (skollar@albany.edu). Virginia Strand, DSW is a Professor at the Fordham University Graduate School of Social Service, West Harrison, NY and the University Partnership Facilitator at the National Child Welfare Workforce Institute (strand@fordham.edu). Robin Leake, Ph.D is an Associate Professor at the University of Denver Graduate School of Social Service, Denver, CO and the Lead Evaluator at the National Child Welfare Workforce Institute
} 
platforms offer friending, following, and commenting features while social media channels allows for the creation of private groups, document sharing, and email lists. The differences between community platforms and social media are lessening while interfaces and sharing of content across platforms (e.g., "share on Twitter") is increasing.

Despite increasing use of online community platforms and social media in social work, concerns remain that social workers are not being adequately prepared to use technology (Giffords, 2009; Hitchcock \& Battista, 2013; Kilpeläinen et al., 2011; Parrott \& MadocJones, 2008; Perron, Taylor, Glass, \& Margerum-Leys, 2010; Young \& Delves, 2009) and that social work organizations are underutilizing these online tools (Baker, Warburton, Hodgkin, \& Pascal, 2014; Edwards \& Hoefer, 2010). Social work programs play an important role in introducing to students how they can use social media and online communities in their professional work and in instructing students in the use of these technologies. There are a variety of ways in which social work educators and schools can integrate social media and/or online communities into courses or programs. For example, course instructors might require students to enroll in an online community for students in the course or integrate blogging into course assignments. Programs might require students to develop professional profiles on LinkedIn or create an online portfolio.

This article examines the National Child Welfare Workforce Institute's (NCWWI) development of an online peer network to support BSW- and MSW-level students participating in child welfare traineeship program. It details the establishment, development, and growth of an online peer network that utilized two popular online platforms (Ning and Facebook) and presents results from the program evaluation.

\section{Online Peer Networks and Communities of Practice in Social Work}

Due to the stressful nature of their work, social workers and social work students may greatly benefit from the support and camaraderie of a peer network (Bergart \& Simon, 2005). While in-person networking may be preferable, it is not always a realistic option for social workers who have major constraints on their time, work in rural areas, and/or have few on-site professional development opportunities (Bergart \& Simon, 2005). Online communities offer professionals and students more options for networking and may better meet their professional, social, and practical needs (Dunlap \& Lowenthal, 2011). Students or professionals of color and those in rural areas may particularly benefit from online communities which can connect them with professionals from different backgrounds and introduce them to a wider array of professional opportunities (Davis, Deil-Amen, RiosAguilar, \& González Canché, 2012; Davis \& Goodman, 2014).

Wenger, White, and Smith (2009) view technology and community as interactive; in their view, the right platform can contribute to a community's sustainability and help a community build a sense of identity and purpose. Selecting a platform or social media site that best meets potential members' needs is important. Organizations or instructors may want to survey potential members during the selection process. 


\section{Literature Review - Principles and Practices for Building Effective Online Communities}

An art and science to building effective online communities has emerged. Prior to developing an online community for the traineeship students, NCWWI staff reviewed the literature on best practices and principles for building successful online communities. Online communities must be well facilitated (Berlanga, Rusman, Bitter-Rijpkema, \& Sloep, 2009; Charalambos, Michalinos, \& Chamberlain, 2004; Wenger, MacDermott, \& Snyder, 2002). Simply making a community available does not mean people will join or actively participate. A facilitator must understand how to build a strong and sustainable community (Backer, 2008; Fayard \& DeSanctis, 2005; Waltonen-Moore, Stuart, Newton, Oswald, \& Varonis, 2006), set the stage for positive member interaction by modeling a friendly conversational rhythm (Fayard \& DeSanctis, 2005), guide the group in resolving and negotiating conflicts (Berlanga et al., 2009; Charalambos et al., 2004; Olofsson, 2007), seek feedback from members on the strengths and challenges of the community, and direct solution-focused discussions around identified challenges.

Community facilitators should understand how to motivate members to participate. Cultivating a dedicated core group of members who consistently contribute to the community and model active participation is one tool for increasing motivation (Wenger et al., 2002). A facilitator also should create a safe space for members to interact (Backer, 2008; Charalambos et al., 2004; Gerard, 2012). One option is to offer varying levels of privacy within the site (e.g., only friended profiles can see certain posts) (Berlanga et al., 2009).

Facilitators must also learn how to increase member commitment. They should limit the size of a community and narrow its focus (Backer, 2008; Kraut, Resnick, \& Kiesler, 2012). They should create opportunities for members to shape the structure, function, content, policies, and operations of the community (Berlanga et al., 2009). Encouraging social and professional interaction (Backer, 2008; Dunworth, 2009) may also increase commitment. Social presence theory suggests members will feel more satisfied and connected to their community (Ho, Quinton, Zia, Laubach, \& Bittner, 2012) when they sense other members are real people and when they are able to express their thoughts and feelings authentically (Lowenthal, 2010).

\section{NCWWI Student Traineeship Peer Network: Program Description}

Over the last decade, attention to the recruitment and retention of competent child welfare staff has become a priority in the field (DePanfilis \& Zlotnik, 2008). Schools of social work have responded to this challenge with educational programs designed not only for currently employed child welfare staff returning for graduate degrees but also by preparing social work students at both the BSW and MSW levels for child welfare practice (Zlotnik \& Pryce, 2013).

It is within this context that two federal initiatives emerged which supported child welfare traineeship programs at schools of social work. One was the NCWWI, which from 2008-2013 focused on building the capacity of the nation's child welfare workforce and supporting the development of skilled child welfare leaders. Twelve traineeship programs 
prepared a diverse group of BSW and MSW students for client-centered practice informed by child welfare and leadership competencies. A second federal initiative started in 2008 also supported traineeship students through five Child Welfare Comprehensive Workforce projects.

The NCWWI student peer network supported BSW and MSW students from 17 traineeship programs. The student peer network coordinator ("the coordinator"), in partnership with NCWWI staff and traineeship program faculty, was responsible for the network's development and implementation. The three main goals of the peer network were to offer students opportunities for professional and leadership development, professional and social networking, and peer support for improved practice. The central components of the peer network were two online communities and a webinar series.

\section{Online platform}

The team chose Ning after considering a number of platforms including LinkedIn, an email listserv, Google group, and Wikispace. Ning sites are customizable for private groups and offered a wider variety of features than other platforms. The Ning site included personalized member profile pages, a chat room, private messaging, a discussion forum, blog space, photo and video sharing, closed and open groups, content pages, event calendar, and an option to add external apps. The Ning site was easy to set up and customize. An informal survey was sent to new traineeship students each fall to gather information about their interests to generate useful content for the site early on.

Ning allowed for social and professional interaction in a safe space. Only traineeship students were invited to join the site, and the coordinator and several other staff members were the only non-student members of the site. Discussion forums (see Figure 1), groups, the blog space, and an event calendar offered space for professional networking while photo-sharing and private messaging offered space for social interaction as well.

The peer network was marketed through a flyer, a letter from the coordinator to new traineeship students, presentations by staff during student orientations (either virtual or inperson), and by faculty. At the beginning of the first year of the program, all traineeship students who provided a valid email address were invited to join the site. Upon joining, new site members were required to answer several profile questions including year in the program, program name, and fieldwork site. They could include more detail in their profile by answering optional questions related to their professional experience and career goals.

\section{Webinars}

All traineeship students, including site members, were invited to participate in professional development webinars. Initial webinar topics were selected based on an informal poll of peer network members. Webinar topics included how to achieve quality, commitment, and competence in the child welfare workforce; secondary traumatic stress; systems of care; and career development. Professionals from the field as well as seven students were presenters. Webinars were recorded and archived on the Ning site for later viewing. 
Figure 1: Ning Site Discussion Forum

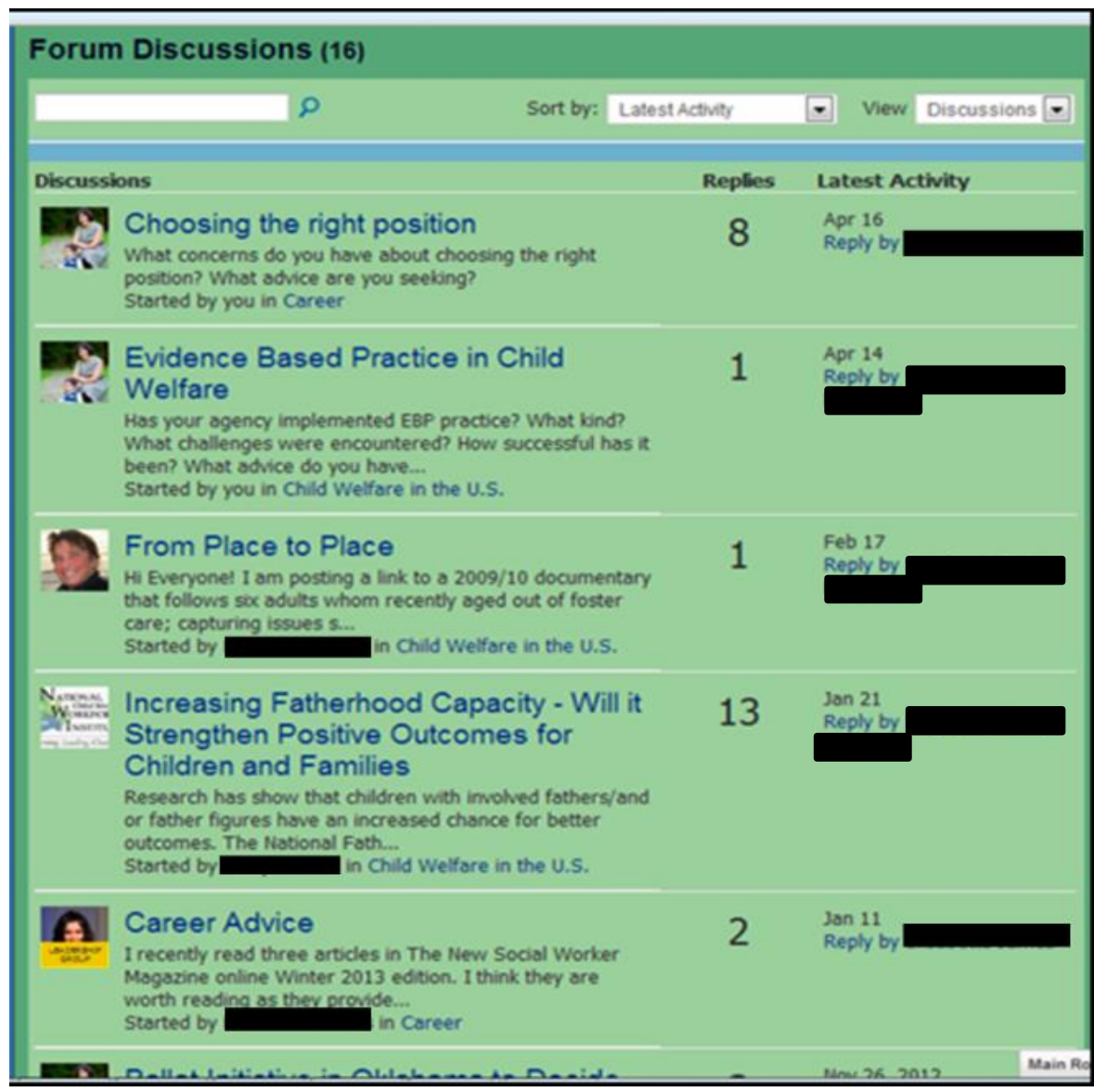

\section{Leadership Group}

To motivate students to participate in the peer network, the coordinator organized a student leadership group that guided peer network activities and modeled active participation. Over four years, the leadership group included five to nine students from different schools.

\section{Program Developments}

To ensure the community was well facilitated, the coordinator's hours were increased during the second year. This allowed more time to add site content, obtain feedback from members, and write to individual members to encourage them to participate. To encourage professional networking, the coordinator created groups on the site around specific topics and schools. Group features included discussion posting and resource sharing. Members of groups were offered the option of meeting by teleconference, but only several calls were held due to difficulty in finding a time when all members of a group could meet. 
Towards the end of year two, in response to student and faculty feedback, the coordinator developed a Facebook group to complement the Ning site. Facebook group features include status updates; photo, video, and link sharing; a calendar; document uploading; and polls. All students were invited to join the group by the beginning of year three. Also in year three the coordinator began sending Ning site members weekly ebulletins that profiled students, highlighted resources, and listed upcoming events. A monthly update also was sent to program faculty to keep them updated about student peer network activities and resources.

\section{Evaluation}

The traineeship peer network team worked with NCWWI program evaluators at the Butler Institute for Families at the University of Denver to develop evaluation questions to help answer the following research questions: 1) How successful was NCWWI in developing a peer network that engaged BSW and MSW students and supported their professional development, and 2) How can the peer network be improved and maximally benefit student members?

\section{Method}

Questions about the peer network were embedded in the traineeship program's formal survey of students, the Stipend Student Inventory (SSI), which focused on student competencies and experiences. The SSI was administered annually online via Qualtrics to all BSW and MSW traineeship students at program entry in the fall, in the spring, and in the summer after students graduated. The peer network section of the SSI asked questions about site and feature usage, participation in webinars, and the usefulness of other activities.

The coordinator gathered additional evaluation data by observing member activity on both sites, using Google Analytics, reviewing webinar evaluations, and from informal feedback from faculty. Google Analytics provided data on site visits, page visits, and the location, number of sessions, visits to specific pages, and geographic location of site visitors. Observing activity on both sites allowed the coordinator to monitor which features were used most frequently. Data downloaded from Ning provided information on member log-on patterns (e.g., date of last log-on) and the number of members receiving broadcast messages.

During the first years of the project, the team used evaluation data to enhance program goals and strategies and modify SSI peer network evaluation questions to better capture information about barriers and facilitators to program implementation.

\section{Results}

\section{Member Totals}

Over four years, 245 students participated in one or both of the peer network sites: 233 joined the Ning site and 74 joined the Facebook Group (Table 1). Fifty-two percent of traineeship students joined the Ning site by the end of year four while $16 \%$ joined the 
Facebook Group. Demographic data was available through the SSI for 232 of the 245 traineeships students who joined at least one of the peer network sites. Of those known, $47 \%$ were BSW students while 53\% were MSW students. The racial/ethnic background of the students was $42 \%$ White/Caucasian, 32\% Black or African American, $12 \%$ Latino or Hispanic, 11\% American Indian or Alaska Native, and 2\% Other (i.e., mixed race, Asian, Pacific Islander). The majority of students were female (87\%).

\begin{tabular}{|c|c|c|c|c|}
\hline \multicolumn{5}{|c|}{$\begin{array}{l}\text { Table 1: Cumulative Ning and Facebook } \\
\text { member totals over four program years }\end{array}$} \\
\hline & Year 1 & Year 2 & Year 3 & Year 4 \\
\hline Ning & 50 & 120 & 165 & 233 \\
\hline Facebook & N/A & N/A & 53 & 74 \\
\hline
\end{tabular}

Table 2: SSI respondents by year

\begin{tabular}{|c|c|c|c|c|c|}
\hline SSI & Administered & Recipients & $\begin{array}{c}\text { Completed } \\
\text { Surveys } \\
\text { (Response } \\
\text { rate) }\end{array}$ & $\begin{array}{c}\text { \# Ning } \\
\text { Participants } \\
\text { (\% of completed } \\
\text { surveys) }\end{array}$ & $\begin{array}{c}\text { \# Facebook } \\
\text { Participants } \\
\text { (\% of completed } \\
\text { surveys) }\end{array}$ \\
\hline Annual & Spring 2011 & Students & $127(79 \%)$ & $59(46 \%)$ & 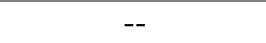 \\
\hline Annual & Spring 2012 & Students & $111(77 \%)$ & $56(50 \%)$ & $34(31 \%)$ \\
\hline Annual & Spring 2013 & Students & $119(64 \%)$ & $40(34 \%)$ & $48(40 \%)$ \\
\hline Follow-up & Summer 2011 & Graduates & $33(50 \%)$ & -- & -- \\
\hline Follow-up & Summer 2012 & Graduates & $101(69 \%)$ & $35(35 \%)$ & $22(22 \%)$ \\
\hline Follow-up & Summer 2013 & Graduates & $121(47 \%)$ & $20(17 \%)$ & $33(27 \%)$ \\
\hline
\end{tabular}

-- = no data due to question not asked

\section{SSI Respondent Demographics}

Table 2 reflects the number of SSI respondents by year. Of the 357 respondents who completed the SSI over four years, $25 \%$ were BSW students and $44 \%$ were MSW students. In identifying ethnicity, 52\% were White/Caucasian, 21\% Black or African American, $15 \%$ Hispanic or Latino, and $8 \%$ American Indian or Alaska Native. The majority of respondents were female $(91 \%)$.

\section{Peer Network Engagement and Usage}

Ning site visits (see definition of "visits" below) increased between years one, two, and three but decreased in year four (see Table 3), perhaps because the program was coming to a conclusion. Use of mobile devices to view the Ning site increased each year. The most frequently used Ning site features were the discussion forum, blogspace, and photo-sharing (see Table 3). The most frequently viewed content on Ning was the home page, member pages, archived webinars, discussion forum, topical groups, and blogspace. School-specific groups were not widely used. One hundred and sixty-five members (71\%) of the Ning site created an expanded profile by answering the optional profile questions while $68(29 \%)$ answered the required questions only.

On Facebook, all discussion posts were viewed by a majority of members although only a small number of members started new discussions. Upon joining the Facebook 
group, students were asked to introduce themselves via a status update, and most did. Like Ning, Facebook activity also decreased in year four.

Figure 2: Ning site visits over four years*

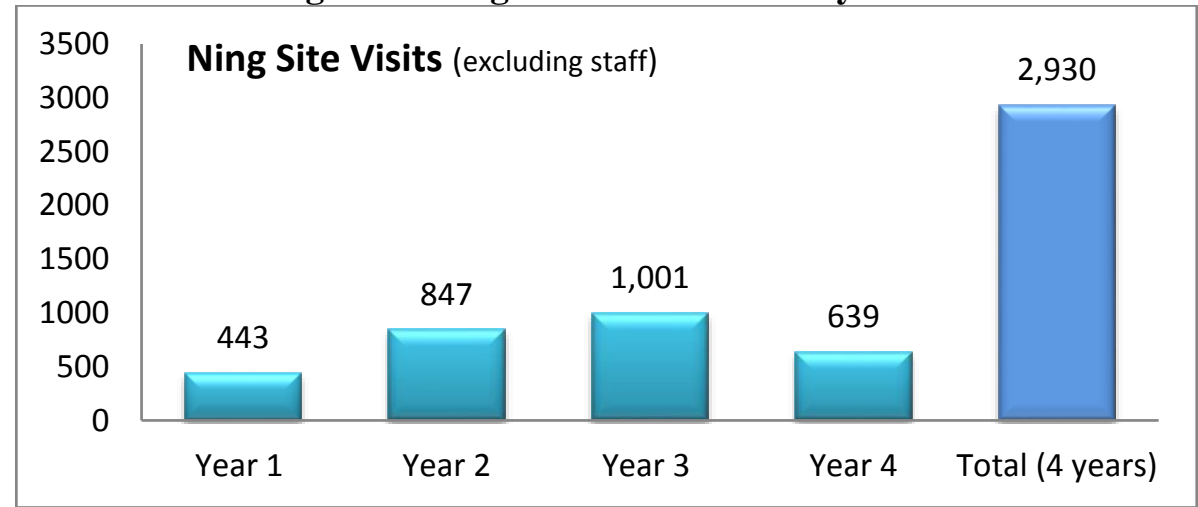

* Site "visits" are defined by Google Analytics as the total number of sessions during the specified date range, including repeat sessions by the same user.

Table 3: Ning and Facebook feature usage over four years

\begin{tabular}{llc}
\hline Ning Site & Deature & $\begin{array}{c}\text { Total by end of } \\
\text { year four }\end{array}$ \\
& Discussion forums & 16 \\
& Discussion forum replies & 61 \\
& Photos posted & 541 \\
& Blog posts & 100 \\
& Blog comments & 14 \\
& Blog views & 14 \\
& Events & 352 \\
& Groups & 47 \\
Group discussions & 15 \\
& Group discussion replies & 16 \\
Gacebook & Group discussion views & 22 \\
Group & Videos posted & 169 \\
* Group comments feature is used to post brief messages but & 16 \\
is not a threaded discussion & 8 \\
**excludes staff posts & 140 \\
\hline
\end{tabular}

\section{Student Satisfaction and Utility Ratings}

According to SSI data, over the duration of the program, students' most frequent reasons given for visiting a site were to access resources, learn about challenges other students were facing, read about upcoming events such as webinars, and learn more about 
content featured in broadcast messages from the coordinator. In 2011, 82\% of Annual SSI respondents said they felt the Ning was easy to navigate. In 2013, 78\% of Annual SSI respondents indicated they received the monthly e-bulletins sent by the coordinator and of those, $71 \%$ found them useful.

In the 2013 Annual and Follow-up SSI, students and alumni reported high overall satisfaction with the peer network since they first joined (70\% of students and 55\% of alumni were satisfied/highly satisfied). Of the students responding to the 2013 Annual SSI, approximately $65 \%$ said resources on Ning were helpful in their coursework and careers, and more than $70 \%$ reported Ning enabled them to connect with other students across the country. Fifty percent of respondents said they received support from other students through the network.

\section{Webinars}

Most students (68\% in 2011 SSI; 66\% in 2012 SSI) unable to attend live webinars cited scheduling conflicts and work/school priorities as the main reasons for not attending. For those who attended, satisfaction with webinars increased each year. In the 2011 SSI, 64\% of respondents said they learned useful information from webinars, increasing to $76 \%$ for students and $91 \%$ for alumni in 2012. Several student presenters noted the experience enhanced their leadership skills and was highly rewarding.

\section{Future Peer Network Activity}

At the end of year four, all SSI respondents were asked how likely they were to participate in a future student peer network hosted on Ning, Facebook, LinkedIn, or an email list serve. More than $50 \%$ of respondents indicated they were likely to participate on any platform, suggesting online peer networking and community building is a useful activity for many social workers and a variety of platforms can be used.

\section{Discussion}

Based on data gathered during four years of the program, the peer network largely met its goals of offering students additional opportunities for professional and leadership development. While it also met its goal of offering students opportunities for professional and social networking, it did not fully meet its goal of facilitating peer support for practice improvement.

Less than half of eligible students participated in the peer network. It became evident during the course of the program that many traineeship students struggle to balance school, work, and family, leaving little time to participate in a peer network. A core group of students regularly contributed to the peer network, and it was evident these students highly valued the peer network. One of these student said she was sorry more students had not actively participated.

The Ning site's capacity to help students co-create and shepherd knowledge was manifest in use of the blog space, discussion forum, and groups. Ning and Facebook offered excellent platforms for fostering professional and social interaction. Student interaction 
on the sites generally centered on professional topics, but frequent photo-sharing, for example, suggests many students also enjoyed the opportunity to interact with other students on a more social level.

Active facilitation was critical to the success of both sites. When the coordinator's time on the project was increased, she was able to engage with students individually and encourage them to make specific contributions such as posting a discussion or writing a blog. The bi-modal distribution of the peer network between students' experience in the field and those with little to no experience necessitated creating a community relevant to each. Informal feedback suggested many experienced students believed the peer network was oriented toward students with less experience. To better engage experienced students, the coordinator developed a webinar, resource page, and group on supervision and management. She also developed a group and several career development webinars for students with less experience.

Schools of social work or traineeship programs interested in supporting students through an online peer network should consider students' level of professional experience. Some students noted they wanted to be engaged in the peer network as professionals, not just as students; therefore, programs may want to shape the peer network to appeal more to students' sense of professional identify.

\section{Evaluation Strengths and Limitations}

The evaluation was primarily developmental in design, allowing the program team to respond to data with needed program modifications. The collaborative approach between the evaluation and programs teams to identify relevant evaluation questions was a major strength of the evaluation. Other strengths included the evaluation's capacity to capture barriers and facilitators to implementation, measure real-time site usage through site observation, and use data from Google Analytics and Ning. As the program evolved, SSI evaluation questions about the peer network were revised. A limitation of the evaluation was the lack of consistency in questions about the peer network from year to year. Although valuable annual data was collected, the team could not compare some measures across student cohorts. Another weakness of the evaluation was the low alumni response rate. Future studies might increase response rates by using pop-up surveys embedded in social media or community sites or by conducting focus groups of users and non-users.

\section{Conclusion}

Increased use of technology can enhance social work education and practice. Schools of social work are encouraged to consider using online community platforms or social media to enhance student comfort with these technologies and to support their learning and professional development. As schools of social work migrate toward offering full or hybrid online education, online community-building for students and professionals will only increase in importance.

Specifically, supporting social work students and alumni as they transition into child welfare careers has emerged as an important issue for educators and administrators (Anderson, Coulborn Faller, \& Leake, 2013). Online communities and social media can 
play a role in the professional socialization of students entering the field (Miller, 2010) and as a transition support for professionals continuing their careers at an agency after earning a professional degree.

A community facilitator of an online community for social work students must be given adequate time to devote to the task of facilitation. He or she must become familiar with the best principles and practices of online community engagement including developing a community identity, creating a safe space, motivating members to participate, and increasing member commitment. The facilitator also should review current literature on social presence in online communities.

Further research is needed to better understand how social work programs can optimally use online communities and social media to support social work students and alumni. Potential research questions include: What is the aptitude of entering students in the use of these technologies? To what extent are programs encouraging use of these technologies? What do we know from social work alumni about how these technologies are being used in the field? With more data, social work educators will be able to further enhance learning with technology.

\section{References}

Anderson, G. R., Coulborn Faller, K., \& Leake, R. (2013). Social work traineeship programs. In K. Briar-Lawson, M. McCarthy, \& N. Dickinson (Eds.), The Children's Bureau: Shaping a century of child welfare practices, programs, and policies (pp. 201-216). Washington, DC: NASW Press. Retrieved from http://www.garymallon.com/spring2014/cw702/2013_003_NASW_ChildrensBureau. pdf\#page $=213$

Backer, T. E. (2008). Peer networking and community change: Experiences of the Annie E. Casey Foundation. Retrieved from Indiana University-Purdue University Indianapolis University Library Philanthropy Archives: https://folio.iupui.edu/bitstream/handle/10244/248/PeerNetworking_full.pdf

Baker, S., Warburton, J., Hodgkin, S., \& Pascal, J. (2014). Reimagining the relationship between social work and information communication technology in the network society. Australian Social Work, 67(4), 467-478.

Bergart, A. M., \& Simon, S. R. (2005). Practicing what we preach: Creating groups for ourselves. Social Work With Groups, 27(4), 17-30.

Berlanga, A., Rusman, E., Bitter-Rijpkema, M., \& Sloep, P. (2009). Guidelines to foster interaction in online communities. In R. Koper (Ed.), Learning network services for professional development (pp. 13-29). Secaucus, NJ: Springer.

Charalambos, V., Michalinos, Z., \& Chamberlain, R. (2004). The design of online learning communities: Critical issues. Educational Media International, 41(2), 135143.

Davis III, C. H. F., Deil-Amen, R., Rios-Aguilar, C., \& González Canché, M. S. (2012). Social media and higher education: A literature review and research directions. 
Retrieved August 14, 2014, from http://works.bepress.com/cgi/viewcontent.cgi?article=1003\&context=hfdavis

Davis, C., \& Goodman, H. (2014). Virtual communities of practice in social group work education. Social Work with Groups, 37(1), 85-95.

DePanfilis, D., \& Zlotnik, J. L. (2008). Retention of front-line staff in child welfare: A systematic review of research. Children and Youth Services Review, 30(9), 995-1008.

Dunlap, J. C., \& Lowenthal, P. R. (2011). Learning, unlearning, and relearning: Using Web 2.0 technologies to support the development of lifelong learning skills. In G. Magoulas (Ed.), E-infrastructures and technologies for lifelong learning: Next generation environments (pp. 292-315). Hershey, PA: IGI Global.

Dunworth, M. (2009). Supporting students through social networking. Journal of Practice Teaching in Social Work and Health, 9(3), 64-80.

Edwards, H. R., \& Hoefer, R. (2010). Are social work advocacy groups using Web 2.0 effectively? Journal of Policy Practice, 9(3-4), 220-239.

Fayard, A. L., \& DeSanctis, G. (2005). Evolution of an online forum for knowledge management professionals: A language game analysis. Journal of Computer Mediated Communication, 10(4), article 2. doi:10.1111/j.1083-6101.2005.tb00265.x

Gerard, J. G. (2012). Linking in with LinkedIn: Three exercises that enhance professional social networking and career building. Journal of Management Education, 36(6), 866-897.

Giffords, E. D. (2009). The internet and social work: The next generation. Families in Society: The Journal of Contemporary Social Services, 90(4), 413-418.

Greenhow, C., \& Robelia, B. (2010). Educational and social benefits of social network sites: Applications to human services. In S. Dasgupta (Ed.), Social computing: Concepts, methodologies, tools and applications (Vol. 1, pp. 188-209). Hershey, PA: IGI Global.

Hickson, H. (2012). Reflective practice online - exploring the ways social workers used an online blog for reflection. Journal of Technology in Human Services, 30(1), 32-48.

Hitchcock, L., \& Battista, A. (2013). Social media for professional practice: Integrating twitter with social work pedagogy [Special issue]. Journal of Baccalaureate Social Work, 18, 33-45.

Ho W., Quinton, A., Xia, J., Laubach, J., \& Bittner, K. (2012). Can Wikis increase students' perception of social presence? A white paper exploring the possibility of increased collaboration and learning outcome. Retrieved February 24, 2015, from The Pennsylvania State University - World Campus http://learningdesign.psu.edu/research2/SocialMediaWhitePaper.pdf

Kilpeläinen, A., Päykkönen, K., \& Sankala, J. (2011). The use of social media to improve social work education in remote areas. Journal of Technology in Human Services, 29(1), 1-12. 
Kraut, R. E., Resnick, P., \& Kiesler, S. (2011). Building successful online communities: Evidence-based social design. Cambridge, MA: Massachusetts Institute of Technology Press.

Lewis, L. A., Koston, Z., Quartley, M., \& Adsit, J. (2010). Virtual communities of practice: Bridging research and practice using Web 2.0. Journal of Educational Technology Systems, 39(2), 155-161.

Lowenthal, P. R. (2010). The evolution and influence of social presence theory on online learning. In T. Kidd (Ed.), Online education and adult learning: New frontiers for teaching practices (pp. 124-139). Hershey, PA: Information Science Reference.

Miller, S. E. (2010). A conceptual framework for the professional socialization of social workers. Journal of Human Behavior in the Social Environment, 20(7), 924-938.

Mishna, F., Bogo, M., Root, J., Sawyer, J.-L., \& Khoury-Kassabri, M. (2012). “It just crept in": The digital age and implications for social work practice. Clinical Social Work Journal, 40(3), 277-286.

Moore, B. (2008). Using technology to promote communities of practice (CoP) in social work education. Social Work Education, 27(6), 592-600.

Murty, S. A., Gilmore, K., Richards, K. A., \& Altilio, T. (2012). Using a LISTSERV ${ }^{\mathrm{TM}}$ to develop a community of practice in end-of-life, hospice, and palliative care social work. Journal of Social Work in End-of-Life \& Palliative Care, 8(1), 77-101.

Olofsson, A. D. (2007). Participation in an educational online learning community. Educational Technology and Society, 10(4), 28-38.

Parrott, L., \& Madoc-Jones, I. (2008). Reclaiming information and communication technologies for empowering social work practice. Journal of Social Work, 8(2), 181197.

Perron, B. E., Taylor, H. O., Glass, J. E., \& Margerum-Leys, J. (2010). Information and communication technologies in social work. Advances in Social Work, 11(2), 67-81.

Quinney, A. (2005). 'Placements online': Student experiences of a website to support learning in practice settings. Social Work Education, 24(4), 439-450.

Waltonen-Moore, S., Stuart, D., Newton, E., Oswald, R., \& Varonis, E. (2006). From virtual strangers to a cohesive online learning community: The evolution of online group development in a professional development course. Journal of Technology and Teacher Education, 14(2), 287-311.

Wenger, E., McDermott, R. A., \& Snyder, W. (2002). Cultivating communities of practice: A guide to managing knowledge. Boston: Harvard Business Press.

Wenger, E. C., White, N., \& Smith, J. D. (2009). Digital habitats: Stewarding technology for communities. Portland, OR: CPsquare.

Young, S., \& Delves, L. (2009). Expanding to fit the (blog)space: Enhancing social work education through online technologies. Same places, different spaces. Proceedings 
ascilite Auckland 2009, 1130-1139.

http://www.ascilite.org.au/conferences/auckland09/procs/young.pdf

Zlotnik, J. L., \& Pryce, J. A. (2013). Status of the use of Title IV-E funding in BSW and MSW programs. Journal of Public Child Welfare, 7(4), 430-446.

\section{Author note}

The authors wish to thank the National Child Welfare Workforce Institute (NCWWI) partners-University at Albany/SUNY, University of Denver, Fordham University, University of Iowa, Michigan State University, University of Michigan, University of Maryland, University of Southern Maine, Portland State University, and the Children's Bureau/ACF/DHHS - whose strong collaboration made this work possible. The work for this publication was funded by the US-DHHS, ACF, Children's Bureau, Award \#90CT0145. This article is solely the responsibility of the NCWWI and does not necessarily represent the official views of the Children's Bureau.

Correspondence can be addressed to boscoruggier@fordham.edu. 